\title{
Anxiety about dental treatment - a gender issue
}

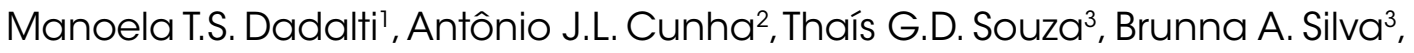 \\ Ronir R. Luiz ${ }^{4}$, Patrícia A. Risso 3 \\ 1. Universidade Federal do Rio de Janeiro, Faculdade de Medicina, Departamento de Clínica Médica, Rio de Janeiro, \\ Brasil. \\ 2. Universidade Federal do Rio de Janeiro, Faculdade de Medicina, Departamento de Pediatria, Rio de Janeiro, Brasil. \\ 3. Universidade Federal do Rio de Janeiro, Faculdade de Odontologia, Departamento de Clínica Odontológica, Rio de \\ Janeiro, Brasil. \\ 4. Universidade Federal do Rio de Janeiro, Instituto de Estudos em Saúde Coletiva, Rio de Janeiro, Brasil.
}

\begin{abstract}
This study compared prevalence and risk factors of dental anxiety between men and women. The sample consisted of 244 participants $(n=122$ men) aged 18 years or older who sought dental care at a public Dental Education Institution from March 2018 to November 2019. The Modified Dental Anxiety Scale was used to determine presence of dental anxiety. The following risk factors were recorded: age, years of schooling, preoperative pain, and type of dental treatment. Bivariate analysis was used to assess the difference in dental anxiety between the sexes. Multivariate logistic regression was used to analyze the association between dental anxiety and gender,
\end{abstract}

regardless of the influence of other variables. Total prevalence of dental anxiety was $18 \%(n=44), 22.9 \%(28 / 122)$ in women and $13.1 \%(16 / 122)$ in men $(p=0.04)$. Gender (odds ratio: 1.83, 95\% confidence interval: 0.92-3.62) and preoperative pain (odds ratio: 2.095 , 95\% confidence interval: 0.97-4.49) were associated with dental anxiety. We concluded that women had a higher prevalence of dental anxiety. Preoperative pain was associated with dental anxiety regardless of gender.

Received: March 2021; Accepted: June 2021.

Keywords: dental anxiety - dental care - gender - pain.

\section{Ansiedade em relação ao tratamento dentário - uma questão de gênero}

\begin{abstract}
RESUMO
Este estudo avaliou a prevalência e os fatores de risco da ansiedade odontológica entre homens e mulheres. $O$ cálculo amostral foi composto por 244 participantes ( $n=122$ homens) com 18 anos ou mais que procuraram atendimento odontológico em uma instituição pública de Educação Odontológica no período de março de 2018 a novembro de 2019. A Escala de Ansiedade Odontológica Modificada foi utilizada para determinar a presença de ansiedade odontológica. Os seguintes fatores de risco também foram coletados: idade, anos de estudo, dor pré-operatória e tipo de tratamento odontológico. A análise bivariada foi usada para avaliar a diferença na ansiedade odontológica entre os gêneros. A regressão logística multivariada foi utilizada para analisar a associação entre ansiedade odontológica e
\end{abstract}

\section{INTRODUCTION}

Dental anxiety is an excessive and unreasonable negative emotional state experienced by patients undergoing dental treatment ${ }^{1}$. Its etiology may be related to previous traumatic experiences ${ }^{2,3}$ such as severe pain or discomfort during or after a dental procedure and negative observations by the dentist ${ }^{2,4}$. gênero, independentemente da influência de outras variáveis. A prevalência total de ansiedade odontológica foi de $18 \%$ ( $n$ = 44), 22,9\% (28/122) nas mulheres e 13,1\% (16/122) nos homens $(p=0,04)$. O gênero (odds ratio: 1,83, intervalo de confiança de 95\%: 0,92-3,62) e a dor pré-operatória (odds ratio: 2,095, intervalo de confiança de 95\%: 0,97-4,49) foram associados à ansiedade odontológica. Concluímos que as mulheres apresentaram maior prevalência de ansiedade odontológica. A dor pré-operatória foi associada à ansiedade odontológica, independentemente do gênero.

Palavras-chave: ansiedade odontológica - tratamento odontológico - gênero - dor.

Dental anxiety can affect the patient's oral health, cause negative thoughts, affect social interactions and job performance, and impact self-esteem and self-confidence, influencing the overall quality of life ${ }^{5,6}$. Anxiety is an important barrier to dental care ${ }^{5}$ because anxious patients tend to miss, delay, or 
cancel appointments, seeking treatment only in acute cases of inflammation and/or infection ${ }^{7}$.Patients with dental anxiety have greater rates of caries, gingivitis, and aggressive periodontitis, which are associated with a negative effect on dental and periodontal health ${ }^{6,8,9}$. Gordon et al. ${ }^{10}$ considered dental anxiety a public health problem and suggested that special attention should be given to these patients due to the consequences of anxiety on oral health. In addition, dental anxiety increases the likelihood of complications occurring during dental intervention ${ }^{11}$, including the onset of systemic changes during dental procedures such as changes in heart rate ${ }^{2}$. A widely used method to assess anxiety level in patients is the Dental Anxiety Scale questionnaire, originally created by $\mathrm{Corah}^{12}$ and later modified by Humphris et al. ${ }^{13}$ and renamed Modified Dental

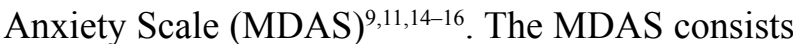
of five questions with five answer options each, in which the aggregate score suggests the overall dental anxiety level of the patient. Studies performed using MDAS report that the frequency of dental anxiety ranged from $8 \%$ to $42.1 \% \%^{9,11,14-16}$. This variation may be related to cultural factors, measurement methods, and the study design ${ }^{17}$.

Factors such as age, education level, duration of the dental procedure, and personality traits have also been reported to influence dental anxiety $4,9,11,14-16,18$. Some studies report that female gender was more closely related to dental anxiety $4,9,11,14,18-20$, while others disagree ${ }^{6,15,16,21}$. It has been reported that men and women tend to express distress differently due to systems that structure gendered behavior ${ }^{22,23}$. However, it is not known whether the factors that influence dental anxiety in men are the same as in women. Furthermore, the studies comparing anxiety according to gender are not methodologically designed to assess gender as a risk factor for dental anxiety and most of them performed an exploratory analysis using convenience samples. Thus, there are limitations in these assessments due to the absence of a sample calculation designed specifically to assess differences in dental anxiety between the genders. The aim of the present study was therefore to evaluate the prevalence and risk factors of dental anxiety in men and women.

\section{MATERIALS AND METHODS Study design and population}

This cross-sectional study was approved by the University Hospital Clementino Fraga Filho of the Federal University of Rio de Janeiro Ethics and Research Committee (No. 1.526.201). All participants were treated in accordance with the Declaration of Helsinki and signed a consent form. The study description followed the recommendations of the Strengthening the Reporting of Observational Studies in Epidemiology criteria.

Sample calculation was based on a predicted prevalence of $15 \%$ for men and double that for women (considering that the average prevalence of dental anxiety was $27 \%$ in previous studies ${ }^{14-16}$ ) with $80 \%$ power and $95 \%$ confidence level. The calculated sample was 244 participants $(n=122$ men and 122 women).

From March 2018 to November 2019, adult patients (age $\geq 18$ years) who sought dental care at a public dental teaching institution were invited to participate in the present study by one of the researchers. The patients included were systemically healthy and received restorative, prosthetic, endodontic, periodontal, or surgical dental treatment immediately after the data-collection interview. Patients who reported psychiatric or physical comorbidities, required highly complex dental treatments, or were pregnant or lactating were excluded.

\section{Risk factors and data collection}

Data were collected through interviews by a previously calibrated examiner (kappa $>0.9$ ). The calibration was performed via a pilot study with 30 participants who answered the questionnaires and then answered again 30 days later under similar clinical situations of dental care. During the interviews, the questionnaire was applied to assess the level of dental anxiety and risk factors such as age, years of schooling, preoperative pain, and the type of dental treatment to which the participant would be submitted on the date of application of the dental anxiety questionnaire.

Preoperative pain was assessed by the question "Are you in pain right now?". When the respondent indicated that pain was present, they were asked to mark the intensity on a visual analog scale $(0$ 170). Age (years) was recorded and patients were stratified into two groups according to age (18-40 and $41-80$ years, respectively) as well as years of 
schooling ( $\leq 12$ years or $>12$ years). Then, to assess the type of dental treatment, two distinct groups were established. One treatment group included participants receiving nonsurgical endodontic treatment, independently of the dental group, and simple surgical treatments such as dental extraction of teeth in occlusion or tooth root, excluding cases with impacted third-molar surgeries and implants. The second treatment group included participants undergoing nonsurgical periodontal treatments such as supra-gingival or subgingival scaling procedures and prophylaxis in general as well as prostheticrestorative treatments such as direct and indirect restorations, cementation of temporary or final prostheses, or manufacture of fixed or removable prosthesis.

The level of dental anxiety among study participants was measured using the MDAS ${ }^{13}$. The scale consists of five questions with five alternative answers, with a value of " 1 " being assigned to the alternative corresponding to the lowest degree of anxiety and " 5 " to the highest degree. Thus, the minimum possible score is five points (without anxiety) and the maximum is 25 points (extreme anxiety). Patients were considered to have dental anxiety when their scores were greater than or equal to $16^{16,24}$.

\section{Data analysis}

The data were entered into the Statistical Package for the Social Sciences version 22.0 software (SPSS for Windows, version 22.0; IBM Corporation, Armonk, NY, USA). The prevalence of anxiety and risk factors (age, years of schooling, preoperative pain, and type of dental treatment) according to each gender was determined. To better explore the influence of gender on anxiety, a multivariate analysis was conducted using a logistic regression model across the sample. For statistical inference, the chi-squared test $(p<$ 0.05 ) and odds ratio (OR) with a $95 \%$ confidence interval (CI) were used.

\section{RESULTS}

A total 256 patients were invited to participate in the study, of whom 244 met the eligibility criteria. Of the total participants included, 44 (18\%) were considered to have dental anxiety according to the MDAS cutoff score of 16 points. The prevalence of dental anxiety was $22.9 \%(28 / 122)$ in women and $13.1 \%(16 / 122)$ in men (odds ratio: $1.75,95 \%$ confidence interval: $1.02-3.01 ; \mathrm{p}=$ $0.04)$. Regarding the other variables studied, the genders were similar, except for the presence of preoperative pain, which was more prevalent in women $(\mathrm{p}=0.04)($ Table 1$)$.

Table 2 shows the distribution of dental anxiety per gender according to the risk factors studied. Dental anxiety was more frequent among female patients with preoperative pain than in those without preoperative pain $(35.7 \%$ vs. $19.1 \%)$.

Multivariate logistic regression analysis including all patients suggests an association between female gender and the presence of dental anxiety (odds ratio: $1.833,95 \%$ confidence interval: $0.926-3.629$ ) and presence of preoperative pain (odds ratio: 2.095, 95\% confidence interval: 0.977-4.492), although the significance level was not reached.

\begin{tabular}{|c|c|c|c|c|}
\hline \multicolumn{2}{|r|}{ Variable } & $\begin{array}{c}\text { Female }(n=122) \\
(\%)\end{array}$ & Male $(n=122)(\%)$ & $\begin{array}{c}P \\
\text { value }\end{array}$ \\
\hline \multirow{2}{*}{ Age (years) } & $18-40(n=108)$ & $49(40.2)$ & $59(48.4)$ & \multirow{2}{*}{0.19} \\
\hline & $41-80(n=136)$ & $73(59.8)$ & $63(51.6)$ & \\
\hline \multirow{2}{*}{ Years of schooling } & $\leq 12(n=149)$ & $71(58.2)$ & $78(64)$ & \multirow{2}{*}{0.35} \\
\hline & $>12(n=95)$ & $51(41.8)$ & $44(36)$ & \\
\hline \multirow{2}{*}{ Preoperative pain } & Present $(n=44)$ & $28(23)$ & $16(13.1)$ & \multirow{2}{*}{0.04} \\
\hline & Absent $(n=200)$ & $94(77)$ & $106(86.9)$ & \\
\hline \multirow{2}{*}{ Type of treatment } & Endodontic and surgical $(n=152)$ & $76(62.3)$ & $76(62.3)$ & \multirow{2}{*}{1.0} \\
\hline & Periodontal and restorative $(n=92)$ & $46(37.7)$ & 46 (37.7) & \\
\hline
\end{tabular}




\begin{tabular}{|c|c|c|c|c|c|}
\hline Gender & \multicolumn{2}{|r|}{ Variable } & Anxious (\%) & $\begin{array}{c}\text { Not anxious } \\
(\%)\end{array}$ & $P$ value \\
\hline \multirow{8}{*}{ Female } & \multirow{2}{*}{ Age (years) } & $18-40(n=49)$ & $13(26.5)$ & $36(73.5)$ & \multirow{2}{*}{0.441} \\
\hline & & $41-80(n=73)$ & $15(20.5)$ & $58(79.5)$ & \\
\hline & \multirow{2}{*}{ Years of schooling } & $\leq 12(n=71)$ & $13(18.3)$ & $58(81.7)$ & \multirow{2}{*}{0.150} \\
\hline & & $>12(n=51)$ & $15(29.4)$ & $36(70.6)$ & \\
\hline & \multirow{2}{*}{ Preoperative pain } & Present $(n=28)$ & $10(35.7)$ & $18(64.3)$ & \multirow{2}{*}{0.067} \\
\hline & & Absent $(n=94)$ & $18(19.1)$ & 76 (80.9) & \\
\hline & \multirow{2}{*}{ Type of treatment } & Endodontic and surgical $(n=76)$ & $19(25)$ & $57(75)$ & \multirow{2}{*}{0.489} \\
\hline & & Periodontal and restorative $(n=46)$ & $9(19.6)$ & $37(80.4)$ & \\
\hline \multirow{8}{*}{ Male } & \multirow{2}{*}{ Age (years) } & $18-40(n=59)$ & $10(16.9)$ & $49(83.1)$ & \multirow{2}{*}{0.225} \\
\hline & & $41-80(n=63)$ & $6(9.5)$ & $57(90.5)$ & \\
\hline & \multirow{2}{*}{ Years of schooling } & $\leq 12(n=78)$ & $11(14.1)$ & $67(85.9)$ & \multirow{2}{*}{0.667} \\
\hline & & $>12(n=44)$ & $5(11.4)$ & $39(88.6)$ & \\
\hline & \multirow{2}{*}{ Preoperative pain } & Present $(n=16)$ & $3(18.8)$ & $13(81,3)$ & \multirow{2}{*}{0.474} \\
\hline & & Absent $(n=106)$ & $13(12.3)$ & $93(87.7)$ & \\
\hline & \multirow{2}{*}{ Type of treatment } & Endodontic and surgical $(n=76)$ & $12(15.8)$ & $64(84.2)$ & \multirow{2}{*}{0.407} \\
\hline & & Periodontal and restorative $(n=46)$ & $4(8.7)$ & 42 (91.3) & \\
\hline
\end{tabular}

\section{DISCUSSION}

In this study, a prevalence of $18 \%$ for dental anxiety was observed and the condition was more common among women. This finding of a female predominance is controversial as it has been corroborated by some studies ${ }^{4,9,11,14,18-20}$ but not reported by others ${ }^{6,15,16,21}$. Such differences in the literature could be attributed to personal and socioeconomic differences ${ }^{17}$ as well as methodological differences such as study design, analysis methods, type of measurement of dental anxiety, and sample size.

However, given the multidimensional nature of anxiety $^{17}$, sociodemographic and preoperative factors were also explored in this study. The male and female groups were similar, except concerning the frequency of preoperative pain, which can be explained by the greater perception of pain stimulation by women ${ }^{25,26}$. However, when initially explored through bivariate analysis (Table 2), preoperative pain did not show association with female or male gender.

In sequence, considering that the difference in preoperative pain between groups could be a confounding factor, a multivariate logistic regression analysis was performed, grouping all study participants together $(n=244)$ and adopting anxiety as an outcome, gender as a variable exposure, and the other variables studied as potential confounders. In this model, the interaction between gender and preoperative pain was ruled out and female gender and the presence of preoperative pain proved to be factors that may increase the chance of dental anxiety. The chance of dental anxiety occurring was 1.8 times greater among women, similar to a previous study ${ }^{9}$, and was two times greater among those who had preoperative pain. Other studies have suggested that the presence of preoperative pain may influence the frequency of dental anxiety ${ }^{4}$ and vice versa ${ }^{27}$, which may impact the sensitivity to pain even during dental care ${ }^{28}$. Other factors such as age, educational level, and type of dental treatment did not show a variable association with dental anxiety between the genders. However, our results cannot be directly compared with those of previous studies because other studies did not analyze these factors according to gender. Studies that evaluated the association of anxiety to other factors without exploring gender found that dental anxiety did not differ according to age ${ }^{6,15,16}$, though there is not complete consensus on this point ${ }^{9,11,14,18}$. Previous studies have considered that the older the patient, the more often they visit the dentist, which can minimize dental anxiety ${ }^{9,14,18}$. Nascimento et al. ${ }^{16}$ and Yakar et al. ${ }^{11}$ showed that the 
fewer the patient's years of schooling, the higher their level of dental anxiety, while other studies did not report such an association ${ }^{6,15,19,21}$. Further, it has been reported elsewhere that the type of dental treatment does not influence the frequency of anxiety ${ }^{16,28}$.

The method used in the present study to assess and identify anxious patients was the MDAS questionnaire $^{13}$, which has been validated in different language ${ }^{29,30}$, is easy to apply ${ }^{31}$, and is widely used $^{6,3,9,11,15,16,18,21,29}$. Moreover, we decided to apply the questionnaires immediately prior to initiating dental care or the procedure because patients were experiencing all of the sensations, including any emotional responses, triggered by the imminent care. Dental anxiety questionnaires have limitations because they are subjective and their outcomes are influenced by patients' responses. All anxiety questionnaires were filled out by patients and some

\section{ACKNOWLEDGMENTS}

The authors would like to acknowledge the support of Fundação Carlos Chagas Filho de Amparo à Pesquisa do Estado do Rio de Janeiro (FAPERJ), Brasil.

\section{DECLARATION OF CONFLICTING INTERESTS}

The authors declare no potential conflicts of interest regarding the research, authorship, and/or publication of this article.

manoeladadalti@gmail.com

\section{REFERENCES}

1. Cianetti S, Lombardo G, Lupatelli E, Pagano S et al. Dental fear/anxiety among children and adolescents. A systematic review. Eur J Paediatr Dent 2017;18:121-130.

2. Liau FL, Kok S, Lee J, Kuo R et al. Cardiovascular influence of dental anxiety during local anesthesia for tooth extraction. Oral Surg Oral Med Oral Pathol Oral Radiol Endod 2008;105:16-26.

3. Humphris G, King K. The prevalence of dental anxiety across previous distressing experiences. J Anxiety Disord 2011;25:232-236.

4. Muglali M, Komerik N. Factors related to patients' anxiety before and after oral surgery. J Oral Maxillofac Surg 2008;66:870-877.

5. Cohen SM, Fiske J, Newton JT. The impact of dental anxiety on daily living. Br Dent J 2000;189:385-90.

6. Kanaffa-Kilijanska U, Kaczmarek U, Kilijanska B, Frydecka D. Oral Health Condition and Hygiene Habits Among Adult Patients with Respect to Their Level of Dental Anxiety. Oral Health Prev Dent 2014;12:233-239.

7. Armfield JM. What goes around comes around: revisiting the hypothesized vicious cycle of dental fear and avoidance. Community Dent Oral Epidemiol 2013;41:279-287.

8. Levin L, Zini A, Levine J, Weiss M et al. Dental anxiety and may not have answered the questions sincerely. We also consider the fact that patients were waiting to be attended to by undergraduate dentistry students, which could artificially inflate the level of dental anxiety, to be a limitation of the present study.

According to Sadi et al. ${ }^{31}$, dental anxiety is a common phenomenon, being one of the main reasons why many people avoid dental care ${ }^{32}$. Dental anxiety not only affects the patient's quality of life $\mathrm{e}^{5,6}$ but also makes the care of these patients more challenging ${ }^{4}$. To adopt an appropriate and successful treatment approach, adapted to the concerns of these patients, dentists first need to identify such patients 7 , which would enable them to apply more appropriate dental management protocols in such cases.

We conclude that women had higher prevalence of dental anxiety. Preoperative pain was associated with anxiety, regardless of gender.

\section{FUNDING}

None.

\section{CONTACT INFORMATION}

\section{Dr. Manoela Dadalti}

Prof. Rodolpho Paulo Rocco, $325,2^{\circ}$ andar - Cidade Universitária, Rio de Janeiro, RJ, CEP: 21941-913

Brasil

oral health-related quality of life in aggressive periodontitis

patients. Clin Oral Invest 2018;22:1411-1422.

9. Guentsch A, Stier C, Raschke Gf, Peisker A et al . Oral health and dental anxiety in a German practice-based sample. Clin Oral Investig. 2017;21:1675-1680.

10. Gordon D, Heimberg RG, Tellez M, Ismail AI. A critical review of approaches to the treatment of dental anxiety in adults. J Anxiety Disord 2013;27:365-378.

11. Yakar B, Kaygusuz Tö, Pirinçci E. Evaluation of Dental Anxiety and Fear in Patients who Admitted to the Faculty of Dentistry: Which patients are more risky in terms of dental Anxiety. Ethiop J Health Sci 2019;29:719-726.

12. Corah N. Development of A Dental Anxiety Scale. J Dent Res 1969;48:596.

13. Humphris GM, Morrison T, Lindsay SJ. The Modified Dental Anxiety Scale: validation and United Kingdom norms. Community Dent Health 1995;12:143-150.

14. Viinikangas A, Lahti S, Yuan S, Pietilä I et al. Evaluating a single dental anxiety question in Finnish adults. Acta Odontol Scand 2007;65:236-240.

15. Kanegane K, Penha SS, Munhoz CD, Rocha RG. Dental anxiety and salivary cortisol levels before urgent dental care. J Oral Sci 2009;51:515-520.

16. Nascimento DL, Araújo ACS, Gusmão ES, Cimões R. 
Anxiety and fear of dental treatment among users of public health services. Oral Health Prev Dent 2011;9:329-337.

17. Armfield Jm, Pohjola V, Joukamaa M, Mattila AK et al. Exploring the associations between somatization and dental fear and dental visiting. Eur J Oral Sci 2011;119:288-293.

18. Caltabiano ML, Croker F, Page L, Sklavos A et al. Dental anxiety in patients attending a student dental clinic. BMC Oral Health 2018;18:48.

19. Kheir OO, Ziada HM, Abubakr NH, Abdel-Rahman ME et al. Patient-dentist relationship and dental anxiety among young Sudanese adult patients. Int Dent J 2019;69:35-43.

20. Zinke A, Hannig C, Berth H. Psychological distress and anxiety compared amongst dental patients- results of a cross-sectional study in 1549 adults. BMC Oral Health 2019;19:27.

21. Dou L, Vanschaayk MM, Zhang Y, Fu X et al. The prevalence of dental anxiety and its association with pain and other variables among adult patients with irreversible pulpitis. BMC Oral Health 2018;18:101.

22. Behler R, Donnelly R, Umberson D. Psychological Distress Transmission in Same-sex and Different-sex Marriages. J Health Soc Behav 2019;60:18-35.

23. Luna MJ, Ameli RN, Cheringal J, Panahi $S$ et al. Gender Differences in Psycho-Social-Spiritual Healing J Womens Health (Larchmt) 2019;28:1513-1521.

24. Haugejorden O, Klock KS. Avoidance of dental visits: the predictive validity of three dental anxiety scales. Acta Odontol Scand 2000;58:255-259.

25. Bartley EJ, Fillingim RB. Sex differences in pain: a brief review of clinical and experimental findings. $\mathrm{Br} \mathrm{J}$ Anaesth 2013;111:52-58.

26. Pieretti S, Di Giannuario A, Di Giovannandrea R, Marzoli F et al. Gender differences in pain and its relief. Ann Ist Super Sanita 2016;52:184-189.

27. Svensson L, Hakeberg M, Wide U. Dental pain and oral health-related quality of life in individuals with severe dental anxiety. Acta Odontol Scand 2018;76:401-406.

28. Lin CS, Wu SY, Yi CA. Association between Anxiety and Pain in Dental Treatment: A Systematic Review and Metaanalysis. J Dent Res 2017;96:153-162.

29. Gupta G, Shanbhag N, Puranik MP. Cross-Cultural Adaptation of Kannada Version of Modified Dental Anxiety Scale Among an Adult Indian Population. J Clin Diagn Res 2015;9;ZC34-38.

30. Facco E, Gumirato E, Humphris G, Stellini E et al. Modified dental anxiety scale: validation of the italian version. Minerva Stomatol 2015;64:295-307.

31. Said H, Finkelman M, Rosenberg M. Salivary Cortisol, Salivary Alpha Amylase, and the Dental Anxiety Scale. Anesth Prog 2013;60:46-53.

32. Rayman S, Dincer E, Almas K. Managing Dental Fear and Anxiety. N Y State Dent J 2013;79:25-29. 